\title{
Tastes of the 'Mongrel' City \\ Geographies of Memory, Spice, Hospitality and Forgiveness
}

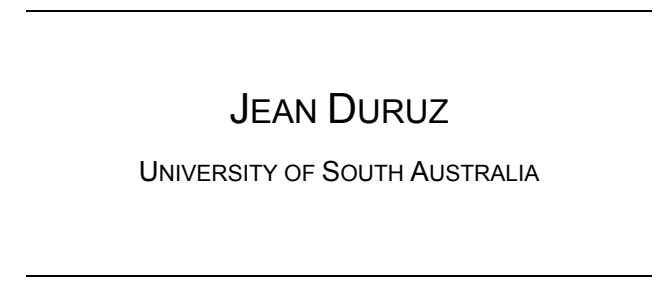

Injera is an Ethiopian flat bread ... usually made from ... teff ... a cereal grain widely grown in Ethiopia for human consumption, but in other countries as fodder ... Teff flour is not readily available in Western shops ... [but resourceful e]xpatriate Ethiopians have evolved different ways of making injera outside of Ethiopia.

Dorinda Hafner ${ }^{1}$

The object invested with sensory memory speaks ...

C. Nadia Seremetakis ${ }^{2}$ 


\section{-ON THE SCENT}

Until recently, Yenenesh Gbere had not seen her mother in Addis Ababa for more than thirty years. Nevertheless, the tastes of chile-spiced stews, together with the sour flavours and spongy textures of Ethiopia's traditional flat bread-injera-have travelled well. These dishes, reinvented by Yenenesh after her arrival in Australia in 1992, are now staples on the menu of Addis Ababa Café, a small 'ethnic' business in the city of Adelaide's western suburbs. Its menu offers, for home-sick Ethiopians and other nostalgic travellers, imagined comforts of 'home'. In the same neighbourhood, Gaganis Brothers, wholesalers of Greek, Mediterranean and Middle Eastern foods, 'sell everything from fresh, dried and tinned goods to giant spit barbecues and huge pots for authentic sauce making'. ${ }^{3}$ With products stacked high in its cavernous interior, Gaganis' warehouse provides essential ingredients for Yenenesh's cooking or, when these are unavailable, possibilities for creative substitution. Meanwhile, down a suburban side street, the African Village Café operates behind closed doors. Open these doors and you'll find young men around a pool table, smell the coffee, hear the sounds of conversation. Opposite, another Ethiopian business-a restaurant and late-night bar-prepares for its customers. From midday, cooking aromas and sporadic sounds of African music drift through the side streets ... past California-style bungalows, shady English trees, scrawny rose beds and lawns exhausted by long, hot summers.

This article examines fragments like these-stories of local places and people, traces of affective landscapes-to chart micro-spatialisations of 'Africa' in a historically 'mixed' Australian neighbourhood. ${ }^{4}$ The project essentially is a geographic one. It maps not only 'lived' and culturally specific uses of urban spaces but also regimes of emotional exchange and sensory knowledge ${ }^{5}$-embedded responses to one of the postcolonial city's critical challenges. The question that haunts everyday life in our 'mongrel cities' is, of course, how is it possible for different people to live together? ${ }^{6}$

This is a question that, increasingly, has become a significant one for cultural theorists, human geographers, sociologists and policy-makers alike. For Gill Valentine, for example, the pressing concern is 'how we might forge a civic culture out of difference'; ${ }^{7}$ for Leonie Sandercock, it is to collectively forge 'new hybrid cultures and spaces'; $^{8}$ for Ien Ang, to capture, productively, the ambivalent 
resonances of 'together-in-difference'; ${ }^{9}$ for Iris Young, to celebrate, unashamedly, social life as a state of 'togetherness-in-difference' with its 'many mestiza spaces and many mestiza people'. ${ }^{10}$ So, to align these theoretical and political imperatives with those drifting, late afternoon smells of Ethiopian cooking in my neighbourhood, we might be tempted to ask: do meanings of 'Africa' sit comfortably among a plurality of 'other' meanings in the streets and businesses of Adelaide's Mile End and its neighbouring suburbs, while retaining a distinctive, and perhaps edgy, presence? How might people living in neighbourhoods characterised by diverse populations be imagined to 'rub along' together? ${ }^{11}$

The complex textures that 'rubbing along' engenders, however, are not always evident in recent cultural analyses. Both David Bell and Gill Valentine claim that a tendency in current theorising to celebrate new kinds of encounters, new forms of sociality in the urban everyday, is, to some extent, problematic. Although this trend might seem to represent a more productive approach for engaging with difference than its opposite (demonising cities as sites of danger, and the presence of strangers as threatening), such literature of celebration provides little insight into the dynamics of everyday encounters. According to Valentine: 'Much of the writing that is associated with what might be regarded as a "cosmopolitan turn" in thinking about the city celebrates the potential for forging new hybrid cultures and ways of living together with difference but without actually spelling out how this is being, or might be achieved in practice'. ${ }^{12}$ Likewise, Bell reflecting on ways that the meanings of hospitality within global cities are being reimagined, especially in regard to refugees and asylum seekers, comments: 'Within this work, there have often appeared discussions of "spaces of hospitality", but these spaces have remained largely abstract. ${ }^{13}$

Amanda Wise and Selvaraj Velayutham suggest that a fruitful route to filling in these conceptual gaps-a route to 'understanding how we live with difference'-is to trawl everyday sites for their ethnographic complexities. Ordinary spaces such as shopping malls and food courts, they say, yield much for a keen ethnographic eye:

The food court of our local shopping mall is deliciously rich with everyday multicultural encounters ... All these groups mostly rub along mostly peacefully but there are myriad stories to tell about the interminglings and encounters present there. It can be a site of conviviality, of light-touch 
rubbing along, of competition for space, everyday racism and crosscultural discomforts, of consumption, of inter-ethnic exchange and hybridity, encounter and hospitality. Far from mundane, its everydayness offers a rich array of interpretative possibility... ${ }^{14}$

It is in the spirit of these authors' 'deliciously rich' that I want to examine narrative fragments collected during my explorations of Mile End and its surrounding neighbourhood. On this occasion I want to piece together fragments sketching the emotional contours of a particular Ethiopian business-contours shaped by memory, the senses, meanings of hospitality and intercultural exchange. In testing these fragments for their emotional resonances and 'rubbings', I want to sound an early warning, experienced as a frisson of nervousness that displaces some of the more usual enthusiasm for this task.

While the prospect of mapping 'Africa' in a familiar neighbourhood is a beguiling one (particularly with a personal palate eager for robust, spicy flavours as a result of its training from the street foods of Singapore, Malaysia and Mexico), it is also a project that, theoretically, is haunted by many ghosts. These range from bell hooks' classic critique of mainstream culture's appropriations of meanings of ethnicity as 'spice' to counteract its own suspected blandness to Ghassan Hage's accusations of the "'Anglo"-cosmopolitan eating subject['s]' greedy consumption that tends to produce 'a "multiculturalism without migrants"' to Valentine's questioning of the nature of encounters across borders of ethnicity and other dimensions of difference, including too-ready assumptions that such encounters are necessarily positive ones. ${ }^{15}$ ' $[\mathrm{C}]$ ontact between different social groups alone', Valentine says, 'is not sufficient to produce respect'. ${ }^{16}$ In other words (to arrive at the nub of Valentine's argument), we need to examine such daily life encounters for their capacity to build appreciation of difference, rather than to create a degree of tolerance for it; rather than simply observing, in everyday interactions, a range of civilities that leave unaddressed 'our multiple and intersecting identities' and their positioning in dynamics of power. ${ }^{17}$ So, in spite of these niggling anxieties, we set out to explore the tastes and smells of the 'mongrel city' ('in which difference, otherness, fragmentation, splintering, multiplicity, heterogeneity, diversity, plurality prevail' ${ }^{18}$ - to map, in Ash Amin's words, 'everyday practices and strategies of 
cultural contact and exchange with others who are different from us. ${ }^{19}$ From the first, the motif of spice dogs our footsteps.

\section{-SPICE ROUTES}

Since its opening in Hindmarsh in 2003, the café has received enthusiastic reviews from the local press. ${ }^{20}$ Ann Oliver's is typical: 'Walking in to the Addis Ababa Café is to become swathed in the exotic perfume of Yenensh Gbere's Ethiopian cuisine. It is the smell of spice and ghee and generosity and even on the coldest night it is cosy and warm. ${ }^{21}$ David Sly, another local food writer, agrees, applauding 'the homely Addis Ababa Cafe ... where chef Yenesh Gbere adds a big pinch of spice to rustic dishes $^{22}$ while Rachel Lebihan savours the typical flavours and textures of Yenenesh's cooking:

For a totally, different culinary experience, Addis Ababa serves reasonably priced Ethiopian cuisine ... Doro Wett ... was a dense, spicy stew of chicken legs slow cooked with onions, hot berebere [sic] spice mix, and kibe (clarified butter). Hardboiled eggs were scored and simmered with the stew, soaking up the spicy juices. ${ }^{23}$

While all three reviewers juggle, in their writing, the contradictions of being attracted to both the 'exotic' and the 'homely', they are unequivocal in identifying spices as defining aromas and flavours of the café's offerings. Spice (as a shorthand for spice pastes or blends) serves different functions for each writer-sometimes it is a critical element of an emotional regime; sometimes a transformative taste to recreate historical imaginaries of peasant cooking; at times it is deeply embedded in the cooking process itself. Nevertheless, the motif of spice is overwhelmingly present, providing a nostalgic link between the 'there' of Ethiopia and the 'here' of an Australian suburban cafe. This is a spice route that is worth our pursuing, not only to understand how spice is implicated in bringing 'Africa' to the Mile End neighbourhood but also to unravel the potential of spice as cultural capital-as knowledge to trade in the market of 'living together'.

The production of spice, for Yenenesh, requires memories, embodied practices and a childhood apprenticeship:

Yenenesh: [M]y mum [taught me to cook]. We didn't measure actually, but

I know what kind of ingredients there [are] ... When ... [my mum] make it 
first, she put this [ingredient first] and the second this one, third this one, then add to this one, everything has the same step when you put in the spice, not all the same time ... [By t]welve years old we ... [had] cooked everything. ... I didn't go at all to school.

Jean: ... [And] your [own] girls?

Yenenesh: They know how to ... [cook], because one year they work with me here, but ... [one says to me] 'Mum, why should I suffer six hours to four hours to stand ... [over] one saucepan to make [a dish] ...?' [laughter] ${ }^{24}$ Yenenesh's narrative of producing the spice mix and her accompanying gestures ('put this ... and the second ... third this one') recalls the writing of Luce Giard, and of Michael Hernandez and David Sutton, especially in regard to the poignancy of hands and gestures for remembering, and the significance of embodied learning from mothers. Hernandez and Sutton reflect on this process:

We have been intrigued by recent thinking on 'embodied memory' and memory storage, that is, the extent which cooking techniques can be seen as explicit mental 'blueprints'. In other words, what might it mean to speak of cooking memory as residing not in our heads but in our hands? ${ }^{25}$

By way of example, Sutton and Hernandez document 'traditional' techniques that a 'modern' Greek housewife uses in her well-equipped Thessaloniki kitchentechniques learnt from her mother and grandmother, such as separating the white from the yolk of an egg using one's hands ... using three fingers against a bottle of oil to measure the depth needed ... cupping a hand to measure vinegar. ${ }^{26}$

Luce Giard mirrors, in her writing, these actions of touch and remembering, describing such embodied practices as 'doing-cooking'. Showing little interest as a child and daughter in learning to cook, Giard discovers, in adulthood, a pattern of memory traces, imprinted through the senses, from time she spent at the kitchen table:

Yet my childhood gaze had seen and memorized certain gestures, and my sense memory had kept track of certain tastes, smells and colours. I already knew all the sounds: the gentle hiss of simmering water, the sputtering of melting meat drippings, and the dull thud of the kneading 
hand ... Thus, surreptitiously and without suspecting it, I had been invested with the secret and tenacious pleasure of doing-cooking. ${ }^{27}$

Giard continues in this vein. While she dubs 'doing-cooking' as 'a very ordinary intelligence', she also imbues it with an almost cosmic significance, its choreography verging on the poetic:

doing-cooking is the medium for a basic, humble and persistent practice that is repeated in time and space, rooted in the fabric of relationships to others and to one's self, marked by the 'family saga' and the history of each, bound to childhood memory just like rhythms and seasons. This women's work has them proliferate into 'gesture trees' ... into Shiva goddesses with a hundred arms who are both clever and thrifty: the rapid and jerky back and forth movement of the whisk whipping egg whites, hands that slowly knead pastry dough with a symmetrical movement, a sort of restrained tenderness. ${ }^{28}$

Is Giard's lyricism justified, we might ask? Is she being overly romantic? Perhaps. Nevertheless, in Yenenesh's account there are pervasive echoes of both 'doing-cooking' and Hernandez and Sutton's 'hands that remember'. Yenenesh's description of preparing the spices presumes you, as the learner, watch the gestures of the cook as she adds ingredients one at a time and that you, in your turn, repeat her actions. The recipe thus becomes an organic process, a performance. This is very different from the way a recipe may be written, with its list of instructions but failure, sometimes, to differentiate the sequence for adding ingredients or to specify long, slow cooking to release the aromas and flavours of the spice mix. ${ }^{29}$ As well, drawing on Hernandez and Sutton, we note the minimal number of utensils usedthe single image of the pot, its sauce made from the spice mix, simmering for four to six hours (a process deceptive in its simplicity, of course, given the intensity of labour and technique required to produce, in Yenenesh's terms, this 'old generation spice').

At the same time, while hands and head might remember, their 'blueprints' surviving diasporic movement, essential ingredients often are absent. Following memory's spice routes is not always the straightforward task it seems. After arriving in Adelaide, Yenenesh conducted a fruitless search for teff flour for making injera, so decided to use rice flour instead. After all, stories of creative combinations of 
ingredients to produce nostalgic resonances of 'elsewhere' are not unusual in the literature. $^{30}$ Nevertheless, as Yenenesh's story of the search for ingredients continued, it contains a different twist:

[It] was a little bit hard for me the first time. How can I get my spice? How can I get the flavour? ... it take for me one year. I'm thinking, I buy something, I mix it. Still no. And then I try the other thing. I go to buy from Gaganis, I go to buy from the India shop, I go to Asia shop. I will try so many things. And then I start to research. I ... start cooking ... and then one day cook it ... and then cook [it again] ... my flavour, to get it [right, it] take[s] some time ... But I want to ... [remember] my mum['s] cooking and I want my mum's taste. ${ }^{31}$

Taste and smell on this occasion provide precise ways to map the neighbourhood-a search haunted by remembered spices in very particular combinations. This becomes Yenenesh's capital, her store of knowledge on which she draws (particularly in the absence of economic capital). Abarca, in her study of Mexican and Mexican-American women's cooking, says:

The sazón is a corporeal sensual knowledge ... the sazón's sensory-logic, inseparable from food, thus inseparable from the body, values the ordinary, as the activity of cooking and eating, which in turn lead to regain a sense of ourselves as cognitive, bodily creatures. ${ }^{32}$

There are echoes of Giard's 'very ordinary intelligence' here (while sazón itself recalls the Spanish sazonar-to flavour-and the English word, seasoning). Furthermore, Abarca conceptualises thoughtful, creative cooks as 'grassroots theorists' who articulate the philosophical bases of their practices. ${ }^{33}$

If we return to Yenenesh as a 'grassroots theorist', we note that not only does she call on her spice memories of tastes and smells and her capacity to improvise in regard to missing ingredients, but also the way she professionalises her practice as 'research'. At the same time, she expresses these research processes as organic ones (in a similar fashion to her demonstration of adding ingredients to the spice mix):

I'm thinking, I buy something, I mix it. Still no. And then I try the other thing. I go to buy from Gaganis, I go to buy from the India shop, I go to Asia shop. I will try so many things. 
So, rather than Yenenesh's simply summarising the ingredients tested or making abstract statements (I experiment with different combinations), you are actually privy to her thought processes ('I mix it. Still no'). You are also offered insight into the ways these processes are embodied (it is easy to imagine Yenenesh's tasting, smelling, as she mimes this for you and then shakes her head and so on), and offered hints of the cartography of that tasting, smelling ('I go to buy from ... I go to buy from...').

Nevertheless, the search for spice is not simply a project of selecting the right ingredients in the right combination to produce the 'correct' taste. It becomes something more-a research problem to be explored, a methodology for achieving this. Here, we might argue, with Abarca, that this spice 'research' represents a form of weaving theory into practice by a grassroots theorist; a 'grounded' accumulation of capital and skill by an organic intellectual.

We might want to take this argument even further. Certainly, Yenenesh's experimenting with spices redraws the spaces of the café as 'African' space in terms of the memories, emotions and meanings she brings to these spaces (and here, we might glimpse the figure of Hage's nostalgic migrant in search of homely intimations in the 'new' home). ${ }^{34}$ However, this creative practice also reworks conceptions of time and space to inscribe, for Yenenesh, the imaginary of transnational citizen. With her identity vested in meanings of cosmopolitanism and cultural capital, she straddles multiple geographies and circuits of goods within the spaces of 'Gaganis', 'the India shop', 'Asia Shop'. In fact, one might argue Yenenesh herself performs as Hage's 'cosmo-multiculturalist', sifting through the products of 'other' histories and geographies and raiding these, reworking these, as tastes of 'home.'.

At this point I want to capture shades of bell hooks' arguments to create a darker mood. While we might admire the ingenuity and organic intellectualism of the spice-maker, our recognition begs the following question: is this simply a return to romancing the 'exotic' (as in those Addis Ababa Café restaurant reviews where spice was designated as 'exotic', different, noteworthy)? hooks herself, we recall, employs spice as a telling image, evocative in its pungency and beguiling in its potential for appropriation: 'ethnicity becomes spice, seasoning that can liven up a dull dish that is mainstream white culture. ${ }^{36}$ Here, too, we can take hooks quite literally in relation to 'spicing up' food of 'dull' cuisines but also in relation to frisson 
associated with the image of the colonised black woman-the servant/motherfigure who feeds and nurtures the children of white women ... an exoticised figure, mysteriously 'other' yet familiar, wholesome, caring. ${ }^{37}$

I want to counter, however, this imaginary of spice (as one, when prepared for 'white culture', that is necessarily a form of appropriation and colonisation by that culture) or, rather, I want to focus instead on the power of spice for 'hands that remember', hands that do things, and hands that enable reflection. This countering might occur, as other writers have suggested, through those arguments of the agency of the creative cook/small business entrepreneur/'grassroots' researcher but also through an interpretation of memory as emotional capital that not only sustains through past losses but also has the potential to generate future gains. ${ }^{38}$ As Sara Ahmed says, 'emotions work as a form of capital; affect does not reside positively in the sign or commodity, but is produced only as an effect of its circulation.' ${ }^{39}$ In other words, it is not the spice mix itself-its precise recipe, its individual ingredients, its complex flavours, that takes centre stage but the way memory and the senses put 'spice' to work to link past and present; here and elsewhere; mothers and daughters; restaurateur and community; embodied learner and professional 'taster'. It is the 'doing' of Giard's 'doing-cooking' that becomes significant here. After all, as Ahmed reminds us, 'emotions do things, and they align individuals with communities—or bodily space with social space-through the very intensity of their attachments'. ${ }^{40}$ And, in this doing, lies recognised forms of power.

Furthermore, this power of 'doing' - this skill to be traded-is recognised by Yenenesh's family from the very first. Spice as cherished emotional capital flavours Yenenesh's account of establishing the restaurant:

Every Refugee Week ... I take my food there, I make coffee there ... I put [out] my equipment, everything, I show what is the [traditional] dress .... And then suddenly my children ... say, 'Mum ... you prepare your spice. We will try to look for you small store'. And they started to look around ... [One son] pay for the bowl[s], one pay for the chair[s], one ... pay for the table[s]. And then they put together and then they say 'Mum, okay we don't have any cash to give you to start it ... [but you have] your capital, your spice...' [emphasis added] 
In this way, spice, in Yenenesh's narrative, becomes a dominant motif of successful integration as a migrant subject. Spice capital (like cultural capital) provides its owner with a certain amount of cache-knowledge of the 'secret geographies' ${ }^{41}$ of spice-making and entree to its enterprise cultures. When Yenenesh travels to Ethiopia to visit her mother for the first time in thirty years, other family members are required to 'fill in' with cooking in the restaurant. 'They can't make my spice taste as good', she whispers to me conspiratorially on her return. These 'secrets' these cartographies are both inherited ones of a nostalgic migrant subject's remembering and recreating 'home', as well as ones of her own construction within relations of cosmopolitanism to reference 'home' through imaginative 'borrowings'. Teasing out these fragmentary accounts of Yenenesh's spice trade, the firm outlines of Hage's distinction of the homesick migrant's homebuilding and the rapacity of the cosmopolitan's desire for 'other' tastes begin to look a little fuzzy, to say the least. ${ }^{42}$

\section{- HOME RULES}

Entering Addis Ababa Café, we could describe it as a mis-en-scéne of 'home'. ${ }^{43}$ Reviewers have been quick to pinpoint the cafés intimations of homeliness, particularly in relation to nostalgic tastes. Rebecca Gill, for example, describing examples of small 'ethnic' restaurants in Adelaide, advises:

If you want to know the cheapest places to eat in the city, check with the university students ... For Ethiopian student, Michael Wege ... getting a taste of his homeland is an enjoyable treat. 'I just catch the bus and come here [to Addis Ababa Cafe] when I want to eat some Ethiopian dishes', he says. 'It has my traditional foods, and the price is fair' ... As a boy growing up in Ethiopia, men were never allowed into the kitchen. As a result, $\mathrm{Mr}$ Wege says he has not yet learned how to cook his favourite foods properly, so loves Addis Ababa, where it tastes like home. ${ }^{44}$

Here consumption of familiar food ('it tastes like home') is embedded in relations of nurturance. Presumably, the food not only tastes like home but also feels like home. Hence, emotional regimes of care take on an added significance in this home-fromhome. This overlay of feeling to acts of consumption raises a number of analytical issues. For example, do theorists such as Jean Baudrillard-in his preoccupations with enclosed systems of signs that perpetually reference each other (as distinct 
from referencing actual commodities) ${ }^{45}$-take emotional regimes of economic exchange into account? In the consumption of 'homely' spaces, do we expect that hospitality in these settings to be a more complicated transaction than a simple payment of money for products and services? David Bell, writing on the ways that new spaces of hospitality in urban centres generate feelings of conviviality, points out these initiatives in urban planning are not ones based wholly in relations of commercial exchange: 'What is at stake is a collective, creative endeavour to produce and reproduce staff-to-customer and customer-to-customer hospitableness as a concrete enactment of a new way of living in cities. ${ }^{46}$

Certainly, Addis Ababa Café takes its hospitableness seriously, with customers responding accordingly. Its welcome extends not only to the local Ethiopian community but also to extremely diverse communities of 'others' (students, working-class people, foodies, vegetarians, other 'others', for example visiting Singaporeans) who pass through its doors. ${ }^{47}$ Its following includes members of the online community, with examples of comments posted online reflecting customer enthusiasm for hospitality experienced:

'... the whole 'African' experience at Addis Ababa is incredible! Yenenesh and her team (Zed, Mel, Teddy and Mikki) do a fantastic job ... ! From the moment you walk in the door, you're part of the family! ... My family loves Addis Ababa...; ${ }^{48}$

'This place certainly stands out above the rest, it has a fantastic family atmosphere and the food is to die for. The food is cooked with love and that radiates throughout the whole experience. An African gem!'; ${ }^{49}$

In true Ethiopian custom, you are made to feel very welcome. You are usually welcome to join another group (of Ethiopians) to share a big group meal, where you will be treated to discussion and information about Ethiopian heritage and culture. You ... will most likely want to book Ethiopia as your next travel destination. ${ }^{50}$

At this point, perhaps, we need bell hooks' image of 'ethnicity as spice, seasoning' to return, and perhaps, too, Ghassan Hage's argument of the cosmo-multiculturalist fantasy: the white cosmopolitan wants ethnic providers 'to "cook-for-themselves-incommunity" for him. ${ }^{51}$ Hage develops this argument in later writing by criticising 
the politics underlying performances of 'ethnic' cultures-exhibitions of food, dance and music at festivals that 'enrich' mainstream culture without intervening in overall power structures. ${ }^{52}$ Admittedly, shades of performance for us flit through all three comments above. While a sense of legitimate belonging is sought by these enthusiastic customers - the warmth, kindness, generosity and acceptance one would expect from one's 'real' (if idealised) family-there is evidence of frequent shifts in identity positioning. On one hand, comments seek to ground identities in familial landscapes - those of being 'part of the family' where 'food is cooked with love' and 'you're made to feel very welcome'; on the other, to adopt the positioning of outsider-tourists enjoying the spectacle of 'the whole "African" experience' ... 'An African gem' ... 'your next travel destination'.

However, while 'Africa' certainly is mapped on the spaces of Addis Ababa Café, the question arises: whose 'Africa' is being negotiated here and what are the rules of engagement? On whose terms are you invited to become 'part of the family' and to participate in 'eating together differently'? ${ }^{53}$ I want to explore these questions and once again through the motif of hands-this time not in relation to cooking but to eating and participating in rituals of culture. I particularly want to tease out rules in regard to hand washing, eating injera and eating together-their symbolism of sharing and forgiveness. In other words, I want to explore in hands that remember, and in hands that learn, the very conditions of hospitality.

Once inside the café, we are immediately aware of the significance of hands as utensils for eating. This requires enacting certain rituals of washing before sitting down to eat. However, for Ethiopians and 'others', there are subtle differences in how these rules are presented. Yenenesh explains these: '[To e]very one ... I say first ... "Wash hand". "Why?" I say wash hand means, if I talk as [in] my culture, "We respect our table" to wash hand[s]. When I'm talking as Australians [so, it's] "Hygiene". [laughter]

While the significance of hand washing before meals is normalised in the Ethiopian community, once strangers appear within the gates, forms of 'education' become necessary. ${ }^{54}$ We note Yenenesh's creativity in straddling cultures here. Different views of how to arrive and eat at the table collide (use, or not, of utensils; preparation of hands as body etiquette; meanings of 'respect', of 'hygiene') but any conflict of interest is addressed in a culturally appropriate/politically strategic way. 
As well, there are compromises-implements are available on request (but not immediately in evidence on the table); large serving spoons for stews and individual plates are provided, and injera, the circular flat-bread, is cut and rolled into individual servings for those who prefer not to eat entirely in the 'traditional' fashion of pulling pieces of injera from a collective plate. Nevertheless, it is a soft-key approach to cultural difference, in which hand-washing practices are explained but, ultimately, is an activity that is, of course, optional. Often customers themselves serve as hosts. By their own example, 'regulars' induct other customers into café rituals. Hence the restaurant becomes a hybrid/mestizo space in which differing values meet, and compromises can be effected.

After hand washing, the next ritual requirement for hands is bread-breaking. Remember Michael Wege, the Ethiopian student in search of cheap meals in Adelaide and ones that embody the taste of 'home'? This is his description of how to eat injera:

The injera is good here. It's a thin, wide pancake. It's like chapatti and you roll it and you eat your food with it ... In most African restaurants, there is no fork, no knife, no spoon-only fingers. ${ }^{55}$

Rachel Lebihan, food journalist for the Australian Financial Review, offers a similar description of injera and how to eat it when served with a stew at Addis Ababa Café: injera, traditional thin bread-a cross between a pancake and a crumpetwhich was far bigger than the dinner plate. The trick to eating the dish, [Yenenesh's son] Zed explained, was to put a spoonful of Doro Wett on top of the injera, top it with a little lyeb (home-made cheese that resembles dry cottage cheese) then pull off the injera and scoop up the stew. ${ }^{56}$

Other food writers, likewise, focus on injera as one of the critical and distinctive food elements of Ethiopian cuisine. Maeve O'Meara, for example, predicting that injera will feature among 'ethnic foods' that have 'already crossed the cultural divide in Australia to become mainstream', describes injera as:

like a large, savoury pikelet with a flat side where it has been cooked on a griddle, and a crumpet-like side filled with little holes ... The meal is eaten by tearing off small pieces of the bread and scooping up some of the stew, then finally the bread with all the juices is eaten. ${ }^{57}$ 
Ann Oliver similarly savours injera's tastes and the technologies of eating it: 'everything comes served with the wonderful injera, the big thick sour spongy pancakes that are integral to the meal and are used to spoon up the food' ${ }^{58}$ Dorinda Hafner elaborates on qualities of commensality that injera might encourage:

For big communal meals, food such as doro wat ... is served directly on to injera ... The bread is then broken off from around the edges to scoop up the stew. The idea is to eat from the outside inwards: very original and a lot of fun for a dinner party idea! ${ }^{59}$

While O'Meara may claim injera has entered the mainstream of Australian tastes, and Hafner that injera has potential fashionability as dinner party novelty, it seems that instruction in how to eat with injera (as well as, actually, to eat it) is still needed. In the examples above, injera is compared to other forms of pan-fried foods made of batter (pikelets, pancakes, crumpets) or other forms of flat-bread (chapattis) to lure potential eaters by stressing injera's recognisable qualities rather than its strangeness. Here, a form of de-exoticisation is taking place: injera is represented as having similar characteristics to other everyday foods, particularly foods associated with traditional Anglocentric and Americocentric meanings of home cooking and comfort. ${ }^{60}$ Even chapatti, commonly eaten with Indian fast food and in mainstream Indian restaurants, might strike a familiar chord. The Ethiopian student's example is a particularly interesting one as it focuses on how food itself can be put to work: like injera, chapatti is used as both food and utensil. ${ }^{61}$ Other 'western' examples in the quotations above tend to be vehicles for spreads, toppings, fillings (butter, honey, maple syrup and so on) rather than specific tools for eating. Hence, a step closer to the 'strange' of injera is achieved through introducing chapatti as its 'not-quite-so-strange' counterpart in taste, texture and technological application.

Hands, and especially fingers, once again come into prominence. These, variously in the quotations above, 'roll ... [injera] and eat your food with it'... '[tear] ... off small pieces of the bread and ... [scoop] up some of the stew' ... '[use injera] to spoon up the food' ... 'put a spoonful of Doro Wett on top of the injera, top it with a little lyeb [cheese] ... then pull off the injera and scoop up the stew' ... '[break] off [pieces] from around the edges to scoop up the stew'. These are hands that not only roll, tear, scoop, spoon up, break off pieces and so on but are also evocative of other 
actions, such as licking one's fingers or smelling the aroma of spices on them long after the meal has finished.

Significantly, hands are also, for Adelaide's Ethiopian community, 'hands that remember'. These hands are not alone in this, of course, as Claudia Roden, doyenne of Middle Eastern cooking points out:

Sometimes [in the Middle East] people break off a piece [of bread] and double it over to enclose and pick up a morsel of meat or vegetable, or dip it in a sauce or cream salad, holding it delicately between the thumb and first two fingers ... Some people, my father among them, claim they cannot truly savour sauces or juices ... without a piece of bread. ${ }^{62}$

Here, O'Meara's instruction for eating injera above would seem to more than fulfil Roden's father's requirement. Technologies of eating and the tools themselvesfingers, bread-offer complex and lingering tastes of 'home'. For hands, however, that do not remember (at least for these intents and purposes), explanation and practice is necessary. While such hands may not be used here to 're-member' (in the sense Anne-Marie Fortier talks about diasporic communities re-working hybrid identities and re-establishing community membership ${ }^{63}$ it is possible that repeated rituals over time like hand-washing and bread-breaking constitute the formation of 'new' memories and new practices of difference for these 'other' hands to adopt. This is hardly a transformation of values on a dramatic scale, but rather forms of incremental creep towards 'different' ways of using hands and 'different' remembering. These are the sort of mundane gestures that Ash Amin recognises, examples of 'small practical accommodations that work their way around, or through, difference, rather than any conscious attempt to shift the cultural identities and practices of local residents'. ${ }^{64}$

\section{- SHARING IN THE VILLAGE}

Sitting companionably inside with Yenenesh in the hour or so before the café opens, I comment once again on its atmosphere of homeliness. Yenenesh replies: 'I want the people don't see it like a restaurant. This is not a restaurant. This is the village house. ${ }^{65}$ Our conversation drifts on. Yenenesh points to a low, circular wicker table with a domed woven lid, and says: 'This one [is mesob] ... at New Year, Christmas 
time, we put food inside and people sit around.' The symbolism of the mesob (or mosobe) is explained in Aster Ketsala Belayney's The Recipe of Love:

Traditionally, it is believed that no matter how many people share our food, we all eat from one plate (or one mosobe). Food is made in a circular form, even our injera (bread) is made in a circular form like the moon or earth or other planets. When we share, we believe that there will always be enough food to share with everyone. ${ }^{66}$

The sharing of food, particularly when seated around one plate with everyone's hands called into play, does not simply amount to ritualised gestures of hospitality. Yenensh explains that in such sharing not only is an economy of love in operation but also one of forgiveness:

I teach how to eat by hand and I explain how to eat together ... [and] the meaning ... [of] that. ... Because [at] that plate eating together, when two people disappointed or something, forgiveness is coming. Don't forget we eat together when we say that. I forgive you. ${ }^{67}$

Here, at 'that plate', hands not only share in acts of commensality but hands also become symbolic of reconciliation (as they do in Sea of Hands, the ongoing campaign for Indigenous rights in Australia) ${ }^{68}$

At Addis Ababa Café then, we might argue that forms of 'light-touch' pedagogies are in place. ${ }^{69}$ Hand-washing, eating with hands and sharing food are optional for customers, and practices are flexible enough to incorporate, to a degree, the rituals of the 'others'. However, despite the staff's obvious need to bend the 'rules' to accommodate 'strangers' at the table (offering rice as a substitute for injera; cutting and rolling injera into individual serves; providing serving spoons and side plates; not selling alcohol but allowing customers to bring their own; accepting tips but donating these to a children's charity in Kenya, and so on), the café becomes a space of agency for its proprietors. There is less sense of cooking 'for them' and more of learning to eat with us, however incomplete, limited and partial diners' attempts may be to engage with cultural difference and to question their own taken-for-granted ways of 'being-in-the world'. ${ }^{70}$

This generosity of sharing and inducting, of course, is not without negative effects, as studies of small businesses in Australia have shown. ${ }^{71}$ Valentine too points to the stresses of maintaining ethnic businesses-the emotional burden of being 
cultural entrepreneurs, figureheads for the community. ${ }^{72}$ Similar stories could be told of the costs of maintaining Addis Ababa Café's regime of hospitality. These would be stories, particularly in relation to Yenenesh, of the long hours, hard labour, little profit, ill-health, extreme fatigue and a heavy sense of cultural responsibility derived from her elder status in her community. A more recent, and not unsurprising, turn of events to add to these would be the decision Yenenesh made, on her return from a visit to Ethiopia, to hand over the running the café to her youngest son, Zed, and his wife, Mel. Such stories of personal hardship and sacrifice would provide a strong counterpoint to the comforting imagery of a welcoming, affordable space with its delicious food and a presiding figure who dispenses maternal love, and, at the same time, provides gentle introductions to cultural difference.

Nevertheless, the creation of spaces in which to welcome 'others', wield authority and grant compromise, even in an interstitial or limited sense, enables us to reflect on the productiveness of Derrida's position on hospitality, and on forgiveness, as paradoxical. Writing on the seemingly unresolvable contradiction of how to provide hospitality freely to all, on one hand, while, on the other, retaining control over the spaces and over processes of selecting recipients of that hospitality (in order to, in fact, be a 'host'), Derrida says:

It is a question of knowing how to transform and improve the law, and of knowing if this improvement is possible within an historical space which takes place between the Law of an unconditional hospitality, offered $a$ priori to every other, to all newcomers, whoever they may be, and the conditional laws of a right to hospitality, without which The unconditional Law of hospitality would be in danger of remaining a pious and irresponsible desire... ${ }^{73}$

A similar argument is advanced by Derrida in relation to forgiveness, whereby absolute forgiveness requiring no apology for pain caused appears in direct contradiction to conditional forgiveness which demands apology as recompense for that pain. ${ }^{74}$ In other words, argues Barnett, drawing on Derrida (drawing, in turn, on Levinas), 'responsible action lies in the divisibility of borders and the finitude of boundaries, but not in their erasure. Thresholds are the very scenes for the drama of responsiveness, hospitality and responsibility'. ${ }^{75}$ All the same, finding that elusive 
'space ... between' for Derrida's 'improvement' or achieving Barnett's fragile balance of divisibility and finitude, of responsibility and responsiveness, might seem an impossibility.

At the threshold of Addis Ababa Café then, such challenges are played out in a microcosm: who is in need of hospitality or forgiveness here? Who, in fact, is the host and who is the guest ... who is positioned in a community of belonging, who is the stranger? Who is at 'home' (even when only peripherally, or in a fantasy sense)? And where is home? And, as Yenenesh adapts to Adelaide and draws on Adelaide's rich non-African culinary traditions to try to reproduce the tastes of her homeland, who is really the cosmopolitan, after all? In response, it might be tempting to argue that this is simply a tale of the 'good migrant' or 'good refugee' (compared to the 'bad muslim', the 'terrorist' in our midst) ${ }^{76}$ who, acknowledging the nation-state's largesse returns its hospitality in kind-in hard work, productivity, neighbourliness, loyalty, civic pride. But I would like to suggest from the other side of the thresholdfrom Addis Ababa Café's interior spaces-that this tale of the 'good' citizen-refugee is probably more textured than such an analysis might suggest.

Consider Yenenesh's loaves and fishes-style account of feeding the hungry at the café:

Sometimes, three times a day ... [people say they can't pay immediately], I say ... oh please, if you're hungry come eat. ... I'm not sit[ting] here for richness. I'm not com[ing] here for wealthy ... Maybe he'll eat today and then will be run because he doesn't want to pay double. I say don't worry about it, just forget it. You're hungry—eat. You drink—I give you a drink ... Like feeling I go to my mama's or grandma's house to eat something.' The biblical tones of Yenenesh's response could well be attributed to her oftenexpressed Christian beliefs; 77 at the same time, the ready provision of credit for impoverished customers could be explained in terms of thriftily maintaining one's regular customer base. ${ }^{78}$ More interesting, perhaps, is to observe (as I did, on one occasion) the relationship of host to guest that cuts across the usual parametersthe black, former refugee woman extends assistance to a working-class, white Australian-born man, in ways not dissimilar to the hospitality and support the same woman, during her childhood, was encouraged to offer neighbours in her own village. So, in the provision of food with delayed payment (or through the waiving of 
payment all together), a relation between 'others' is forged, and one that might fleetingly trouble the usual boundaries of class, gender, ethnicity and citizenship history. At the same time, the action is totally consistent with religious and cultural beliefs centred on feeding the hungry and offering comfort to those seeking the warmth, food and shelter within our walls.

Returning to Derrida's conception of duty versus rights of hospitality in his 'cities of refuge',79 this is not to argue that Addis Ababa Café exists outside the constraints of the power of the market, the state or their agencies of governmentality. As well (as I've already pointed out), neither is this to argue that relations within the café mirror, in miniature, those outside-that a benevolent state encourages its 'new' citizens to re-enact this hospitality-to be grateful for largesse and, in the everyday 'local', pass it on. Instead, I'm speculating that embodied memories, tradeable expertise and power and positioning in one's own community to remember, to share as well as to forgive, together provide a strong basis and a critical position for negotiating with myriad 'others' who cross the threshold. After all, it is Narayan who reminds us of the need to shift the emphasis from a westerncentric preoccupation with 'mainstream' and 'others' at the borders and to focus instead (or, at least, as well) on the complex give-and-take of relations on the other side of the threshold, or even to reconceptualise where thresholds lie. ${ }^{80}$ After all, despite ambivalent positioning and constraints, complex meanings of hospitable acts sometimes partly overturn, or at least trouble, geospatial relationships of who is host, who is the stranger, who is being integrated, who is not, who is the teacher, who is being taught... 'In short,' says Amanda Wise, 'it matters who is doing the consuming, where, and among whom.' 81

Now the meal is over. The injera remains as irregular fragments on the plate. The stews are mostly memories carried in the mouth and on the hands of departing diners. But I want to leave the table with two afterthoughts. The first of these is that power needs to be compromised in confronting difference if the 'together' part of the 'togetherness-in-difference' equation is to be realised. In other words, 'multicultural' eating should not be simply 'added in' to experiences of privilege. Instead, even in the most mundane practices of everyday life (like using a knife and fork), a degree of authority can, and should be, relinquished. To acknowledge the 'other' then involves surrendering part of the 'self', or at least democratising the 
identity of 'self'. The second point for reflection is in response to Ghassan Hage's criticisms of 'ethnic' food being commodified to the point that such food becomes detached from its 'ethnic' providers, producing a '"multiculturalism without migrants"' for that 'classy and more often than not ... "Anglo"-cosmopolitan eating subject'. ${ }^{82}$ Undoubtedly such commodification occurs. However, here, in Addis Ababa Café, as a site of Ash Amin's 'micropolitics of everyday social life and encounter', ${ }^{83}$ the relationship between staff and customers, cooks and eaters, eaters and other eaters, is constantly negotiated. 'Migrant' subjects are hardly 'erased' or 'passive' in their challenge to assumptions of who might offer hospitality and forgiveness and to whom. Instead, these subjects are active and insistent agents in a complex politics of reciprocal understanding and exchange.

Jean Duruz is an Adjunct Senior Research Fellow within the Hawke Research Institute of the University of South Australia. Recent publications of hers appear in Continuum, New Formations and Cultural Studies Review. Currently, she is working on projects that focus on ethnic neighbourhoods in Adelaide, Sydney and New York, street food in Singapore and Malaysia and global circuits of food, particularly in port cities of the Indian Ocean and the Strait of Malacca.

\footnotetext{
-NOTES

1 Dorinda Hafner, A Taste of Africa: Traditional and Modern African Cooking, Wakefield, Adelaide, 2002, p. 92.

2 C. Nadia Seremetakis, 'The Breast of Aphrodite', in The Taste Culture Reader: Experiencing Food and Drink, ed. Carolyn Korsmeyer, Berg, Oxford, 2005, p. 303.

3 David Sly, 'World on a Plate', Sydney Morning Herald, 24 October 2009.

<http://www.smh.com.au/travel-feature/world-on-a-plate-20091021-h85g.html>.

${ }^{4}$ Census figures for the City of Charles Sturt (the café's local council area) indicate that in 2006 the residents' main ancestries, other than Australian, were nominated as English, Italian, Irish, Greek, Scottish and German. Between 2001 and 2006, the fastest growing numbers associated with overseas
} 
birthplaces by Charles Sturt residents were for China, India and South Africa. City of Charles Sturt, Community Analyst, Eastern Charles Sturt, pp. 97, 104,

<http://www.charlessturt.sa.gov.au/webdata/resources/files/Community_Analyst_Eastern_Charles_St urt_(PDF).pdf $>$. In terms of the state's Ethiopian community, this numbered less than five hundred residents in 2006 (compared to 4,500 South Africans). Multicultural SA, 'An Overview of South Australian Multiculturalism', Multicultural Life, Autumn 2008, p. 22.

${ }^{5}$ Lisa Law, 'Home Cooking: Filipino Women and Geographies of the Senses in Hong Kong', Ecumene, vol. 8, no. 3, 2001, p. 281.

${ }^{6}$ Leonie Sandercock, Cosmopolis II: Mongrel Cities of the 21st Century, Continuum, London, 2003, p. 1. Sandercock, referring to Salman Rushdie's defence of Satanic Verses, celebrates the productive meanings of 'mongrel' for global cities of late modernity rather the more usual meanings of 'mongrel' as a perjorative in popular discourse.

7 Gill Valentine, 'Living with Difference: Reflections on the Geographies of Encounter', Progress in Human Geography, vol. 32, no. 3, 2008, p. 323.

8 Sandercock, p. 10.

${ }^{9}$ Ien Ang, On Not Speaking Chinese: Living between Asia and the West, Routledge, London, 2001, pp. 193, 200.

10 Iris Marion Young, 'A Critique of Integration as the Remedy for Segregation', in City Visions, ed. David Bell and Azzedine Haddour, Pearson Education, Essex UK, 2000, p. 214.

11 David Theo Goldberg, 'The Space of Multiculturalism, Open Democracy, 16 September 2004, pp. 3-4, $<$ www.openDemocracy.net>; Amanda Wise and Selvaraj Velayutham, 'Introduction: Multiculturalism and Everyday Life', in Everyday Multiculturalism, ed. Amanda Wise and Selvaraj Velayutham, Palgrave Macmillan, Houndsmill, Basingstoke UK, 2009, p. 2; David Bell, 'The Hospitable City: Social Relations in Commercial Spaces', Progress in Human Geography, vol. 31, no. 7, 2007, pp. 2, 20.

12 Valentine, p. 324.

13 Bell, p. 8.

14 Wise and Velayutham, pp. 1-2.

15 bell hooks, 'Eating the Other', in Black Looks: Race and Representation, ed. bell hooks, South End, Boston, 1992, p. 21; Ghassan Hage, 'At Home in the Entrails of the West: Multiculturalism, "Ethnic Food" and Migrant Home-Building', in Home/World: Space, Community and Marginality in Sydney's West, ed. Helen Grace, Ghassan Hage, Lesley Johnson, Julie Langsworth and Michael Symonds, Pluto, Sydney, 1997, p. 118; Valentine; see also Amanda Wise, 'Moving Food: Gustatory Commensality and Disjuncture in Everyday Multiculturalism', New Formations, no. 74, 2012, pp. 83-4.

16 Valentine, p. 326.

17 Valentine, p. 334.

18 Sandercock, p. 1. 
${ }^{19}$ Ash Amin, 'Ethnicity and the Multicultural City: Living with Diversity', Environment and Planning A, vol. 34, no. 6, 2002, p. 976.

20 In 1978, after her husband's death from war injuries, Yenenesh Gbere left her three sons in the care of extended family members in Addis Ababa and fled Ethiopia. Later the children were to join her. For fourteen years she lived in a refugee camp in Kenya. While in the camp, Yenenesh remarried, and gave birth to two daughters. In 1992, the entire family arrived, as refugees, in Adelaide, South Australia. Yenenesh quickly established herself as a prominent volunteer for refugee and community groups and has been awarded for her services accordingly. See 'Special Feature: SAMEAC's 25th Anniversary: Yenenesh Gebre', Multicultural Life, 2005, p. 20.

${ }^{21}$ Ann Oliver, 'A Taste of Africa in Adelaide', Independent Weekly, 14 July 2009,

$<$ http://www.independentweekly.com.au>.

22 Sly.

${ }^{23}$ Rachel Lebihan, 'Spoilt for Choice', Australian Financial Review, 29 December 2009 - 3 January 2010, p. L7.

${ }^{24}$ Quotations attributed to Yenenesh are from an extended interview with Yenenesh Gbere, 4 August 2008. Field observations were recorded during regular visits to the café during the period from July 2008 to April 2009. Digital files of the interview and field notes are in the author's possession. 25 Michael Hernandez and David Sutton, 'Hands that Remember: An Ethnographic Approach to Everyday Cooking', Expedition, vol. 45, no. 2, 2005, p. 31.

${ }^{26}$ Hernandez and Sutton, pp. 32-6.

${ }^{27}$ Luce Giard, 'The Nourishing Arts', in Michel de Certeau, Luce Giard and Pierre Mayol, The Practice of Everyday Life Volume 2: Living and Cooking, University of Minnesota Press, Minneapolis, 1998, p. 153. 28 Giard, pp. 157, 158.

${ }^{29}$ For example, we could compare Yenensh's instructions for the addition of ingredients one at a time and slow cooking of the spice mix with Dorinda Hafner's. Hafner's 'Western version' of berbere requires simply mixing together nine different spices, toasting these a few minutes, adding a further four spices with salt, and then toasting all of these for ten minutes (Hafner, p. 91). Likewise, a readymix packet version of berbere produced by Herbie's Spices <www.herbies.com.au> simply lists ten spices plus salt and then advises the cook just 'to coat meat with berbere before grilling, frying, barbecuing, or browning'.

${ }^{30}$ Hage, 'At Home in the Entrails of the West', pp. 108-9; Angela Heuzenroeder, Barossa Food, Wakefield, Adelaide, 1999, pp. 45-6; 253-55.

31 Note that, in 2005 when Addis Ababa café was established, Adelaide's more common ethnic food cultures would be Greek, Italian, Middle Eastern, South and South East Asian, with various African cuisines a much later and rarer addition, following immigration and refugee patterns. For Adelaide's migration history, reflected in its Central Market, see Catherine Murphy, The Market: Stories, Histories and Recipes from Adelaide Central Market, Wakefield, Adelaide, 2003, pp. 128-36. Note, too, that in 
2006 the state's Ethiopian community was relatively small compared to other African communities and numbered less than five hundred. Multicultural SA, p. 22.

32 Meredith E. Abarca, Voices in the Kitchen: Views of Food and the World from Working-Class Mexican and Mexican-American Women, Texas A \& M University, College Station, 2006, p. 60.

${ }^{33}$ Abarca, p. 81.

${ }^{34}$ Hage, 'At Home in the Entrails of the West', pp. 104-11.

35 Ibid., pp. 118, 132.

36 hooks, 'Eating the Other', p. 21.

37 bell hooks, Ain't I a Woman?: Black Women and Feminism, Pluto, London, 1982, pp, 83-5; see also Jean Duruz, 'Haunted Kitchens: Cooking and Remembering', Gastronomica, vol. 4, no. 1, 2004, p. 60. 38 Ian Cook, Philip Crang and Mark Thorpe, 'Eating into Britishness: Multicultural Imaginaries and the Identity Politics of Food', in Practising Identities: Power and Resistance, ed. Sasha Roseneil and Julie Seymour, Macmillan, Houndmills, Basingstoke UK, 1999, p. 234; Abarca, pp. 80-1.

${ }^{39}$ Sara Ahmed, 'Affective Economies', Social Text 79, vol. 22, no. 2, 2004, p. 120.

40 Ahmed, p. 120.

41 Jane M. Jacobs, 'Resisting Reconciliation: The Secret Geographies of (Post)Colonial Australia', in Geographies of Resistance, ed. Steve Pile and Michael Keith, Routledge, London, 1997.

42 Hage, pp. 134-8. To be fair to Hage, he does discuss the impact of 'cosmo-multicultural' eating on ethnic restaurateurs in terms of how they approach their customers (the knowledge they are expected to have). Nevertheless, he does not accord such providers the possibility that they might be cosmomulticulturalists themselves.

43 Inside the café, numerous artefacts, art works, posters and family photographs adorn the walls. Cooking pots are displayed on low tables. A wash basin is positioned discreetly behind a screen. Prominently displayed, Yenenesh's certificates of recognition from government and community agencies attest to forms of hybridised identity-making and home-building. 44 Rebecca Gill, 'Hunting Down a Bargain Bite', Adelaide Advertiser, 14 November, 2007, Indulge, p. 4. 45 Jean Baudrillard, in Baudrillard Live: Selected Interviews, ed. Mike Gane, Routledge, London, 1993, p. 147; Colin Campbell, 'The Sociology of Consumption', in Acknowledging Consumption: A Review of New Studies, ed. Daniel Miller, Routledge, London, 1995, p. 103.

46 Bell, p. 19.

47 The ethnic diversity of customers was a regular feature of field trip observations. Informal conversation with customers and staff tended to confirm these observations. Regular vegetarian/vegan banquets attracted customers on the basis of such dietary preferences/political food choices as, for example, members of Animal Liberation.

48 See Kit MacFarlane and Jean Duruz, "Technologies of Nostalgia: Vegetarians and Vegans at Addis Ababa Café', in Eat, Cook, Grow: Mixing Human-Computer-Interactions with Human-Food-Interactions, 
ed. Jaz Hee-jeong Choi and Marcus Foth, MIT Press, Cambridge MA [in press]; Michelle, 17 July 2009, posted in response to Oliver, 2009.

49 Janet, 17 July 2009, posted in response to Oliver, 2009.

50 George, posted 26 June 2009, review of Addis Ababa Café on Menufeast website, <http://www.menufeast.com.au/info/5130/addis-ababa-cafe/west-hindmarsh>.

${ }^{51}$ Hage, 'At Home in the Entrails of the West', p. 140.

52 Ghassan Hage, White Nation: Fantasies of White Supremacy in a Multicultural Society, Pluto, Sydney, 1998, p. 118.

53 Jean Duruz, 'Living in Singapore, Travelling to Hong Kong, Remembering Australia ... : Intersections of Food and Place', in Culinary Distinction, ed. Emma Costantino and Sian Supski, API Network, Perth, 2006, p. 114.

54 Department of Immigration and Multicultural Affairs, Commonwealth of Australia, Ethiopian Community Profile, Commonwealth of Australia, 2006, Canberra, p. 14.

55 Michael Wege quoted in Rebecca Gill, p. 4.

56 Lebihan, p. L7.

57 Maeve O'Meara, 'Tongue Twisters', The Weekend Australian Magazine, 28-29 March 2009, p. 28.

58 Oliver, 2009.

59 Dorinda Hafner and William and Dorothy Hall, Ethnodelicious; Eat! Travel! Collect!, Cameron House, Adelaide, 2005, p. 136

${ }^{60}$ Nigella Lawson, How to be a Domestic Goddess: Baking and the Art of Comfort Cooking, Chatto and Windus, London, 2000. Lawson claims in her preface that 'baking stands as a useful metaphor for the familial warmth of the kitchen we fondly imagine used to exist, and as a way of reclaiming our lost Eden'. Recipes for pancakes (American breakfast pancakes, welshcakes, johnnycakes) are included in Lawson's collection (pp. 74-7).

${ }^{61}$ Charmaine Solomon, The Complete Asian Cookbook, Lansdowne, Sydney, 1976, p. 21.

62 Claudia Roden, A New Book of Middle Eastern Food, Penguin, London, 1985, p. 433.

${ }^{63}$ Anne-Marie Fortier, Migrant Belongings: Memory, Space, Identity, Berg, Oxford, 2000, pp. 153-4.

64 Amin, p. 970.

${ }^{65}$ Addis Ababa Café's location could not be less village-like. Situated in a small cluster of suburban shops on a busy highway between the city and the port, the café is easy to overlook. However, a makeover of its premises, instigated by the extended family, has produced a distinctive 'style'-the illusion of a village hut with a shaded verandah, thatched roof and strings of twinkling lights. Inside the walls are covered with mementos from customers' trips to Ethiopia, artworks, family photographs and framed awards for Yenenesh's services to the refugee community of South Australia. Material references to an Ethiopian 'home' here certainly provide a set for touristic performance, though this would seem to be in the spirit of Eric Cohen's 'emergent' authenticity, in which both hosts and guests fully appreciated the contrived aspects of performance, and in which 'authenticity' is produced 'locally' 
as layers of meaning-intimations of remembered and continuing cultures attached to a particular site. Eric Cohen, 'Authenticity and Commoditization in Tourism', Annals of Tourism Research, vol. 15, no. 3, 1988, p. 383.

66 Aster Ketsela Belayneh, The Recipe of Love: An Ethiopian Cookbook, Random Orbit, Toronto, 2006, pp. 173-4.

${ }^{67}$ Cooking as love, with food as a means of reconciling people, is a strong thread in Maria Elisa Christie's book, Kitchenspace: Women, Fiestas and Everyday Life in Central Mexico, University of Austin, Texas, 2008. Christie, reporting on her fieldwork in home kitchens, says 'everyone counts on you to make things right in the kitchen, no matter how things are outside, or how you feel inside', cited in Marilyn L. Tausend, 'Review of Kitchenspace', Gastronomica, vol. 10, no. 1, 2010, p. 162.

${ }^{68}$ Australians for Native Title and Reconciliation (ANTaR) instigated its Sea of Hands Campaign in 1997. The campaign has been to encourage reconciliation between Indigenous and non-Indigenous Australians and to support Indigenous rights. The campaign icon is a massed collection of cutout hands, in the colours of the Aboriginal and Torres Strait Islander flags, designed to be a moveable community art installation, <http://seaofhands.antar.org.au>.

69 Wise and Velayutham, p. 2, refer to 'light-touch rubbing along' as a strategy for sharing space; see also Amin, p. 970, in regard to 'small practical accommodations' as the basis for cultural change.

70 Hage, 'At Home in the Entrails of the West, p. 140; Giard, p. 154.

${ }^{71}$ Jock Collins, Katherine Gibson, Caroline Alcorso, Stephen Castles and David Tait, A Shop Full of Dreams: Ethnic Small Businesses in Australia, Pluto, Sydney, 1995, pp. 157-71.

72 Valentine, p. 331.

73 Jacques Derrida, On Cosmopolitanism and Forgiveness, Routledge, London, 2001, pp. 22-3.

74 Derrida, p. 51.

75 Clive Barnett, 'Ways of Relating: Hospitality and the Acknowledgement of Otherness', Progress in Human Geography, vol. 29, no. 5, 2005, p. 16.

76 Ahmed, p. 132.

77 SAMEAC's 25th Anniversary, p. 10.

78 Janet Long-Solis, 'A Survey of Street Foods in Mexico', Food and Foodways, vol. 15, no. 3-4, 2007, p. 228, reports, in relation to Mexican street food sellers, that vendors customarily allowed regular customers credit.

79 Derrida, pp. 3-5.

80 Uma Narayan, Dislocating Cultures: Identities, Traditions and Third-World Feminism, Routledge, New York, 1997, pp. 183-4, 187.

81 Wise, p. 107.

82 Hage, 'At Home in the Entrails of the West', p. 118.

83 Amin, p. 959. 